\title{
Estimation of toxic elements in the samples of different cigarettes and their impact on human health of Irish hypertensive consumers
}

\author{
Hassan Imran Afridi ${ }^{\text {a,b }}$, Tasneem Gul Kazi ${ }^{\text {b }}$, Farah Naz Talpur ${ }^{\text {b }}$, Dermot Brabazon ${ }^{\text {a }}$, Sumsun Naher ${ }^{\text {a }}$ \\ a Mechanical \& Manufacturing Engineering, Dublin City University, Dublin, Ireland \\ b National Center of Excellence in Analytical Chemistry, University of Sindh, Jamshoro, Pakistan
}

\begin{abstract}
Background: Cigarette smoking interferes with the metal homeostasis of the human body, which plays a crucial role for maintaining the health. A significant flux of heavy metals, among other toxins, reaches the lungs through smoking. In the present study, the relationship between toxic element (TE) exposure via cigarette smoking and hypertension incidence in population living in Dublin, Ireland is investigated. Methods: The different brands of cigarette (filler tobacco, filter and ash) consumed by the studied population were analyzed for cadmium $(\mathrm{Cd})$, nickel $(\mathrm{Ni})$, and lead $(\mathrm{Pb})$. The concentrations of TEs in biological samples and different components of cigarette were measured by inductively coupled plasma atomic emission spectrophotometer after microwave-assisted acid digestion. The validity and accuracy of the methodology were checked using certified reference materials. Results: The filler tobacco of different branded cigarettes contains $\mathrm{Cd}, \mathrm{Ni}$ and $\mathrm{Pb}$ concentrations in the ranges of 1.73-2.02, 0.715-1.52 and 0378-1.16 pg/cigarette, respectively. The results of this study showed that the mean values of $\mathrm{Cd}, \mathrm{Ni}$ and $\mathrm{Pb}$ were significantly higher in scalp hair and blood samples of hypertensive patients in relation to healthy controls, while the difference was significant in the case of smoker patients $(p<0.001)$. The levels of all the three TEs were $2-3$ folds higher in scalp hair and blood samples of non-hypertensive smoker subjects as compared to nonsmoker controls. Conclusion: The high exposure of toxic metals as a result of cigarette smoking may be synergistic with risk factors associated with hypertension.
\end{abstract}

Keywords: Scalp hair, Blood, Different brands of cigarette, Cigarette smokers, Toxic elements, Inductive coupled plasma atomic, emission spectrophotometer,

\section{Introduction}

Hypertension (HT) is an increasingly important medical and public health issue. The prevalence of HT increases with advancing age (60-90 years) [1]. But today, the age criteria have been changed and even people below 30 years of age have HT problems because of the lack of exercise, fast foods, smoking, coffee and alcohol consumption [2]. Genetic effect may also be a factor [3]. Smoking, however, is an important source of exposure to toxic elements (TEs) such as cadmium $(\mathrm{Cd})$, nickel $(\mathrm{Ni})$ and lead $(\mathrm{Pb})$, which have been proposed as causative agents of cigarette smoke-induced physiological disorders [4-6]. In fact, a study showed that serious symptoms (strong urges to smoke, feeling anxious or unsuccessful 
attempts at not smoking) appeared in youth within weeks or only days after the initial start of smoking [6]. Cigarette design has evolved considerably over the last few decades with the incorporation of new tobacco processes, papers, filters and several ingredients (flavor, humectants and casing materials), which either alone or in combination have the potential to modify the quantity and/or the quality of the smoke yielded [7].

The tobacco plant absorbs TEs most probably from the soil, from fertilizers or from pesticides [8]. Other environmental factors that may influence the uptake of TEs by tobacco plants include the $\mathrm{pH}$ of soil, contaminated irrigated water and sewage sludge used as fertilizers. Tobacco smoking delivers 87 organic carcinogens to the lungs, in addition to TEs [9], which may partition into the smoke phase on combustion [10]. Some of these (Cd, Ni and $\mathrm{Pb}$ ) readily pass into the bloodstream and may accumulate in specific organs, such as the kidney and liver [11]. There are a few studies that have reported on the large variations of heavy metal/TEs in the compositions of commercial tobacco products, which have tried to link smoking-related diseases with TEs derived from tobacco combustion [12]. The intake of trace and TEs may promote hypertensive and atherosclerosis disorders by increasing oxidative stress (for example, by catalyzing the production of reactive oxygen species or inhibiting their degradation) due to the deficiency of an antioxidant element and by increasing blood pressure levels [13].

The deficiency of essential nutrients, lack of homeostatic control or an excess intake of some TEs causes chronic physiological disorders, such as HT and cardiovascular disease [14]. Determinations of trace elements in human tissues and fluids were used to obtain information on nutritional status for diagnosis of diseases, indication of systemic intoxication, and to obtain information on environmental exposure [15]. In the majority of cases, whole blood, serum, plasma, and urine were analyzed [16]. One of the most widely used analytical techniques for different element determinations in biological and environmental materials is inductively coupled plasma atomic emission spectrometry (ICP-AES) due to its advantages over other analytical methods: before all a possibility of simultaneous determination of many elements of interest, freedom from different chemical interferences and high detection power. ICP-AES also offers rapid, multi-element determinations. The sensitivity of ICP-AES is lower than that of either inductive coupled plasma mass spectrophotometer (ICP-MS) or atomic absorption graphite tube atom-izer (AA-GTA), but ICP-AES can handle higher levels of total dissolved solids (TDS) than ICPMS and is much faster than AA-GTA $[17,18]$. Since ICP-AES is able to analyze samples with higher TDS, more concentrated solutions can be prepared allowing trace elements to be measured. The main advantage of microwave-assisted sample pretreatment is its requirement of small amount of mineral acids and a reduction in the production of nitrous vapors.

Microwave systems keep blank levels low because only small volumes of reagents are required and allow more samples to be processed per hour than conventional digestion systems [19]. The aim and objective of our present study was to assess the concentrations of $\mathrm{Cd}, \mathrm{Ni}$ and $\mathrm{Pb}$ in the scalp hair and blood samples of smoker and hypertensive patients. For a comparative study, 54 non-hypertensive individuals (smoker and nonsmokers) of the same age group (ranged 30-50 years), socioeconomic status, localities and dietary habits were 
selected as controls. The understudy elements were analyzed by inductive coupled plasma atomic emission spectrophotometer, after microwave-assisted acid digestion. Presently, we also evaluated and compared the status of toxic metals (TEs) $(\mathrm{Cd}, \mathrm{Ni}$ and $\mathrm{Pb}$ ), in different pre-smoking and post-smoking components (filler tobacco, filter and ash) of various imported branded cigarettes existing in Ireland.

\section{Materials and methods}

\subsection{Apparatus}

Agate ball mixer mill (MM-2000 Haan, Germany), was used for grinding the cigarette tobacco, filter and ash. Sieves made of nylon with mesh sizes of $0<50$ and $65 \mathrm{pm}$ were used to study the influence of particle size on extraction. A Varian Liberty 220 (Mulgrave, Victoria, Australia) inductively coupled plasma atomic emission spectrometer with the axially viewed plasma was used for the analysis. The Liberty Series II ICP features a $40 \mathrm{MHz}$ free running RF generator, a $0.75 \mathrm{~m}$ Czerny-Turner monochromator with 1800 grooves $/ \mathrm{mm}$ holographic grating used in up to 4 orders. The resolution of the spectrometer is typically $0.018 \mathrm{~nm}$ in $1 \mathrm{st}$ order, $0.009 \mathrm{~nm}$ in $2 \mathrm{nd}$ order, $0.007 \mathrm{~nm}$ in 3rd order and $0.006 \mathrm{~nm}$ in 4th order. The instrumental conditions are shown in Table 1. A Hinari Life style (Elstree) domestic microwave oven (maximum heating power of $800 \mathrm{~W}$ ) was used for digestion of the scalp hair, blood and different cigarette component samples. Acid-washed polytetrafluoroethylene (PTFE) vessels and flasks were used for preparing and storing the solutions.

Table 1

Measurement conditions for inductive coupled plasma atomic emission spectroscopy Liberty 220 ICP-AES

\begin{tabular}{lcll}
\hline Parameters & Cd & Ni & Pb \\
\hline $\begin{array}{l}\text { Wavelength (nm) } \\
\text { Height (mm) }\end{array}$ & 226.5 & 231.6 & 220.5 \\
& 3 & 5 & 3 \\
$\begin{array}{l}\text { Common parameters } \\
\text { Windows (nm) }\end{array}$ & 0.027 & Nebulizer type & V-groove \\
$\begin{array}{l}\text { Sabove the coil) } \\
\text { Scan (nm) }\end{array}$ & 0.040 & Nebulizer pressure & $150 \mathrm{kPa}$ \\
$\begin{array}{l}\text { Integration (s) } \\
\text { Replicates }\end{array}$ & 3 & Stabilization time & $10 \mathrm{~s}$ \\
$\begin{array}{l}\text { Sample uptake (s) } \\
\text { PMT (V) }\end{array}$ & 3 & Sample delay time & $30 \mathrm{~s}$ \\
& 650 & Rinse time & 105 \\
& & Pump-tube & Orange-orange \\
(inlet) & Blue-blue \\
Power (kW) & & & (outlet) \\
Plasma flow (l/min) & 15.0 & Faft pump & On \\
Auxiliary flow (l/min) & 1.50 & Background mode & Dynamic \\
Pump speed (rpm) & 15 & Max curve order & 1 \\
CC. limit & $n \% 95$ & &
\end{tabular}




\subsection{Reagents and glass wares}

Ultrapure water obtained from ELGA Lab Water system was used throughout the work. Concentrated nitric acid (65\%) and hydrogen per-oxide (30\%) were from Merck and checked for possible trace metal con-tamination. Working standard solutions of $\mathrm{Cd}, \mathrm{Ni}$ and $\mathrm{Pb}$ were prepared immediately prior to their use, by stepwise dilution of certified standard solutions (1000 ppm) Fluka Kamica (Buchs), with 0.5 mo1/1 HNO3. All solutions were stored in polyethylene bottles at $4{ }^{\circ} \mathrm{C}$. For the accuracy of methodology, the certified reference material (CRM), human hair NCSZN 81002b, Clincheck® control-lyophilized human whole blood and Virginia tobacco leaves (ICI-ITJ-cta-VTL-2) were used. All glassware and plastic materials used were previously soaked for $24 \mathrm{~h}$ in 5 mo1/1 nitric acid, washed with distilled and finally rinsed with ultrapure water, dried, and stored in a class 100 laminar flow hoods.

\subsection{Sample collection and pretreatment}

\subsubsection{Cigarette pretreatment}

Five different commercially available branded cigarettes (BCs) were purchased from local market of Dublin (Ireland) during July and August 2010 (Table 2). The samples were in their original packaging, and placed in pre-washed dried plastic bags separately and stored at $4{ }^{\circ} \mathrm{C}$ until test-ed. The weight of each cigarette after dried at $80{ }^{\circ} \mathrm{C}$ was determined. A duplicate 4 composites samples of each branded cigarette $(n=10)$ were taken randomly from 4 different batches (packed on different dates). For analysis of TES in cigarette tobacco, we separated all compo-nents of cigarette, tobacco, filter and wrapping paper of 5 cigarettes of each composite samples and dry it in a sterilized glass beaker for $48 \mathrm{~h}$ at $80{ }^{\circ} \mathrm{C}$, the dried tobacco were ground with agate ball mixer mill and sieved through nylon sieves with mesh sizes of 0 $65 \mathrm{pm}$. The remaining 5 cigarettes of each corresponding composite batch of all branded ciga-rettes understudy were used for smoking by a volunteer to collect ash of cigarette in cleaned PTFE beaker separately at room temperature $\left(30-35{ }^{\circ} \mathrm{C}\right)$. Cigarette smoking termination was carrying out when the burning line reached the butt length (different according to different brands). Care was taken to avoid any source of contamination, and this preparation was done in a clean room.

Table 2

Information of branded cigarettes.

\begin{tabular}{llll}
\hline Sample code & Sample name & Description & Wt/cigarette (g) \\
\hline BC1 $^{4}$ & Dunhill & International, filter deluxe UK & $0.731 \pm 0.008$ \\
BC2 & Pine & Benhson and hedges & $0.548 \pm 0.005$ \\
BC3 & Marlboro & Filter class A cigarettes (USA) & $0.869 \pm 0.015$ \\
BC4 & Silk cut & Japan tobacco & $0.715 \pm 0.009$ \\
BC5 & John Player blue & Nottingham, England. & $0.692 \pm 0.013$ \\
\hline
\end{tabular}

a Branded cigarette. 


\subsection{Biological samples pretreatment}

Before the start of this study, all controls and HT patients of both genders, age range 30-50 years, were informed through a consent form by the administration about the aim of study, and all agreed to participate and signed the form. A questionnaire was also administered to them to collect details regarding physical data, ethnic origin, health and duration of smoking, frequency of smoking, dietary habits, age and consent.

The patients were grouped according to their habits, non-smoker patients (PNS) and cigarette smoker patients (PS). While control group are also divided into 2 groups, first group nonsmoker (CNS) and cigarette smoker (CS), as shown in Table 3. Physical examinations were carried out in a basic health unit of Dublin, Ireland to measure participant's weight, height, blood pressure and biochemical data. For all patients and controls, anthropometric parameters including weight, height and waist circumference were measured using the standard protocols (Table 4).

Table 3

Characteristics of study subjects (30-50) age groups.

\begin{tabular}{llllll}
\hline \multirow{2}{*}{ Parameters } & \multicolumn{2}{l}{ Referents } & & \multicolumn{2}{l}{ Hypertensive patients } \\
& Male & Female & & Male & Female \\
\hline Occupation & 25 & 20 & & 25 & 22 \\
Labor & 18 & 21 & & 25 & 15 \\
Office workers & 15 & 18 & & 19 & 20 \\
Not working & & & & & \\
Habit & 40 & 35 & & 48 & 40 \\
Smoking tobacco & 18 & 24 & & 21 & 17 \\
Nonsmoking tobacco & & & & &
\end{tabular}

Table 4

Clinical and biochemical characteristics of hypertension patients and controls.

\begin{tabular}{|c|c|c|c|c|}
\hline \multirow[t]{2}{*}{ Parameters } & \multicolumn{2}{|l|}{ Controls } & \multicolumn{2}{|l|}{ HT patients } \\
\hline & $\mathrm{CNS}^{4}$ & $C S^{b}$ & PNS & $\mathrm{PS}^{\mathrm{d}}$ \\
\hline \multicolumn{5}{|l|}{ Male } \\
\hline Height $(\mathrm{cm})$ & $180.3 \pm 25$ & $181.6 \pm 0.9$ & $179.6 \pm 1.32$ & $179.8 \pm 0.83$ \\
\hline Weight (kg) & $794 \pm 1.3$ & $82.1 \pm 1.13$ & $80.3 \pm 2.54$ & $82.6 \pm 2.68$ \\
\hline $\begin{array}{l}\text { Waist circumference } \\
\text { (cm) }\end{array}$ & $76.4 \pm 1.19$ & $79.3 \pm 1.21$ & $85.8 \pm 1.02$ & $87.3 \pm 1.16$ \\
\hline BMI $\left(\mathrm{kg} / \mathrm{m}^{2}\right)^{e}$ & $24.4 \pm 2.0$ & $24.9 \pm 0.85$ & $249 \pm 1.6$ & $25.5 \pm 1.34$ \\
\hline Systolic BP (mm Hg) & $119.3 \pm 3.1$ & $122.7 \pm 2.4$ & $1522 \pm 2.8$ & $160.5 \pm 1.06$ \\
\hline Diastolic BP (mm Hg) & $799 \pm 27$ & $83.2 \pm 0.92$ & $96.5 \pm 1.42$ & $99.2 \pm 0.62$ \\
\hline \multicolumn{5}{|l|}{ Female } \\
\hline Height $(\mathrm{cm})$ & $164.2 \pm 1.28$ & $165.2 \pm 1.0$ & $165.1 \pm 0.95$ & $164.3 \pm 0.82$ \\
\hline Weight (kg) & $605 \pm 1.26$ & $62.3 \pm 0.72$ & $62.2 \pm 1.73$ & $64.7 \pm 0.55$ \\
\hline $\begin{array}{l}\text { Waist circumference } \\
\text { (cm) }\end{array}$ & $63.4 \pm 1.06$ & $65.1 \pm 1.30$ & $64.2 \pm 0.85$ & $65.6 \pm 0.63$ \\
\hline $\mathrm{BMI}\left(\mathrm{kg} / \mathrm{m}^{2}\right)$ & $22.4 \pm 1.57$ & $228 \pm 1.65$ & $22.8 \pm 1.57$ & $23.9 \pm 1.74$ \\
\hline Systolic BP (mm Hg) & $119.1 \pm 1.2$ & $120.7 \pm 0.5$ & $150.4 \pm 1.92$ & $158.5 \pm 1.21$ \\
\hline Diastolic BP (mm Hg) & $80.1 \pm 0.93$ & $83.5 \pm 0.61$ & $95.2 \pm 1.25$ & $96.5 \pm 0.47$ \\
\hline $\begin{array}{l}\text { Control nonsmokers. } \\
\text { Control smokers. } \\
\text { Patient nonsmokers. } \\
\text { Patient smokers. } \\
\text { BMI = body mass ind }\end{array}$ & & & & \\
\hline
\end{tabular}


There were no statistically significant differences between both groups of patients and controls with regard to height and weight. Among controls and patients smokers, the range of consumption was of 10-15 cigarettes/day. The 62\% hypertensive patient used antihypertensive drugs. The study protocol was approved by the local ethics committee of Dublin city university, Ireland. The hypertensive patients, who had blood pressure exceeding 130/95 mm Hg (systolic/diastolic), were admitted for their uncontrolled HT and had earlier histories of high blood pressure.

The criteria of healthy subjects included no history of symptoms of hypertension and any coronary disease documented in their medical notes, and no family history of heart disease was defined by a first-degree relative with a myocardial infarction (MI), or cardiac death before the age of 55 years. All control subjects underwent a routine medical examination including MI test. All patients and controls/referents were requested to complete an interviewer-administered questionnaire, concerning their demographic characteristics, age, health history, lifestyle habits, and diet. They gave written consent to participate in the study. There is no difference in the dietary habits of Irish controls and hypertensive patients of both genders. The dietary habits of Irish people (elder age group) depend mainly upon meat (chicken, mutton, lamb) and plants (vegetables and beans) consumption.

The socioeconomic status of understudied Irish people is average. The $>65 \%$ of understudied controls and hypertensive people reported earning more or equal than $€ 320$ per week. All understudied older people had achieved at least secondary education. The elderly have greater susceptibility of increased or decreased levels of elements than younger. Gender is also a factor to consider due to differences in the intake of energy, essential elemental status, or hormonal influences, which can affect the bioavailability of trace elements.

\subsection{Collection of blood and scalp hair samples}

Venous blood samples $(5 \mathrm{ml})$ were collected by using $7 \mathrm{~mm}$ heparinized lithium Vacutainer® tubes (Becton Dickinson). About $2 \mathrm{ml}$ of venous blood samples were stored at $-20{ }^{\circ} \mathrm{C}$ until elemental analysis [19]. The hair samples (-1.0 g each) were taken from the nape of the neck. Hair samples were put into separate plastic envelopes for each participant, on which the identification (ID) number of the participant was indicated. The plastic envelope of each subject was tightly sealed and attached to a questionnaire.

Before analysis, each individual hair sample was cut into approximately 0.5 -cm-long pieces and mixed to allow a representative subsampling of the hair specimen. After cutting, each sample was washed with diluted Triton X-100, then samples were rinsed with distilled water and then with deionized water. The samples were then rinsed three times with acetone [19]. The samples were then dried in an oven at $75 \pm 5{ }^{\circ} \mathrm{C}$ for $2 \mathrm{~h}$. Dried samples were stored separately in polyethylene bags. 


\subsection{Microwave-assisted acid digestion}

A microwave-assisted digestion procedure was carried out, in order to achieve a shorter digestion time. Replicate six samples of each certified and triplicate samples of filler tobacco (FT) of each cigarette brand ( $0.2 \mathrm{~g})$, while filter and ash (obtained from each cigarette), were weighed in PTFE flasks ( $25 \mathrm{ml}$ in volume), added $2.0 \mathrm{ml}$ mixture of concentrated HNO3$\mathrm{H} 202(2: 1, \mathrm{v} / \mathrm{v})$ to tobacco leaves and filter, while acids mixture HNO3-HC1 (1:3, v/v) was used for ash of cigarette, kept all flasks at room temperature for $10 \mathrm{~min}$. Placed flasks in a PTFE container close it and subjected to at $80 \%$ of total microwave energy ( $800 \mathrm{~W}$ ). After cooling, the contents of each flask were heated on electric hot plate to semi dried mass and dissolved in $5 \mathrm{ml}$ of $1.0 \mathrm{M}$ nitric acid and filtered through Whatman filter paper 42, the final volume was made up to $10 \mathrm{ml}$ with de-ionized water as stock sample solutions. Duplicate samples of scalp hair $(200 \mathrm{mg}$ ) and $0.5 \mathrm{ml}$ of blood samples of each hypertensive patients and control subjects individuals were directly placed into Teflon PFA flasks. Two milliliters of a freshly prepared mixture of concentrated HNO3-H202 (2:1, v/v) were added to each flask, left for $10 \mathrm{~min}$. After this period, the flasks were placed in a covered PTFE container. This was then heated following a one-stage digestion program at $80 \%$ of total power $(800 \mathrm{~W})$, during 2-3 min for blood, and 5-8 min for hair samples. After the digestion, the flasks were left to cool and the resulting solution was evaporated to semidried mass to remove excess acid. About $5 \mathrm{ml}$ of $0.1 \mathrm{~mol} / 1$ nitric acid was added to the residue and filtered through a Whatman no. 42 filter paper and diluted with deionized water up to $10.0 \mathrm{ml}$ in volumetric flasks. Blank extractions were carried through the complete procedure. Blanks and standard solutions were prepared in a similar acid matrix. The validity and efficiency of the MWD method was checked with certified values of human hair NCSZC 81002b, Clincheck® control-lyophilized human whole blood, Virginia tobacco leaves (ICHTJ-cta-VTL-2) and with those obtained from conventional wet acid digestion method (Table 5) [20].

\begin{tabular}{|c|c|c|c|c|c|}
\hline Elements & CDM & MWD & Tralué & I recovery & Certified values \\
\hline \multicolumn{6}{|c|}{ Certified sample of human has (us/g) } \\
\hline cd & $0.0716 \pm 0.003(4.19)$ & $0.0714 \pm 0.006(8.40)$ & 0.305 & 997 & $0.072 \pm 0.010$ \\
\hline $\mathrm{Ni}$ & $571+0.51(893)$ & $5.67+0.43(7.58)$ & 0.339 & 994 & 577 \\
\hline $\mathrm{Pb}$ & $3.80 \pm 0.37(9.74)$ & $3.72 \pm 0.35(9.41)$ & 0.081 & 98.05 & $3.83 \pm 0.18$ \\
\hline \multicolumn{6}{|c|}{ Certified sample of whole blood (jeil) } \\
\hline Cd & $0.53 \pm 0.025(4.72)$ & $0.524 \pm 0.024(4.58)$ & 0.2256 & 9887 & $0.52 \pm 0.024$ \\
\hline $\mathrm{Pb}$ & $3329+1.21(3.63)$ & $3256+1.18(3.62)$ & 0.096 & 978 & $33+12$ \\
\hline Ni & $46.07 \pm 1.41(3.06)$ & $45.75 \pm 1.38(3.02)$ & 0.9242 & 99.3 & $460 \pm 1.4$ \\
\hline \multicolumn{6}{|c|}{ Virginin tobarce lofof (ugiz) } \\
\hline cd & $1.52 \pm 0.102(6.71)$ & $1.50 \pm 0.0781(5.20)$ & 0.158 & 98.68 & $1.52 \pm 0.171$ \\
\hline $\mathrm{Pb}$ & $22.3 \pm 0.352(1.57)$ & $21.5 \pm 0.381(1.77)$ & 0.0311 & 96.41 & $22.1 \pm 0.0772$ \\
\hline Ni & $197 \pm 0.201(102)$ & $195 \pm 0.181(9.28)$ & 0.275 & 98.98 & $198 \pm 0.212$ \\
\hline
\end{tabular}




\subsection{Analytical figures of merit}

Statistical analyses were performed using Minitab 13.2. The Student's t-test was used to assess the significance of the differences in concentrations of elements among study subjects. Calibration was performed with a series of $\mathrm{Cd}, \mathrm{Ni}$, and $\mathrm{Pb}$ standards. Sensitivity (m) was the slope value obtained by least-square regression analysis of calibration curves based on absorbance signals. The limit of detection, equal to $0.0003 \mathrm{ng} / \mathrm{mg}, 0.01 \mathrm{ng} / \mathrm{mg}$ and 0.0003 $\mathrm{ng} / \mathrm{mg}$ for $\mathrm{Cd}, \mathrm{Ni}$, and $\mathrm{Pb}$ respectively, was de-fined as $3 \mathrm{SD} / \mathrm{m}$, corresponding to 10 blank injections and ' $\mathrm{m}$ ' the slope of the calibration graph. The quantification limits, defined as 10 $\mathrm{SD} / \mathrm{m}$ were calculated as: $0.0009 \mathrm{ng} / \mathrm{mg}, 0.05 \mathrm{ng} / \mathrm{mg}$ and $0.001 \mathrm{ng} / \mathrm{mg}$ for $\mathrm{Cd}, \mathrm{Ni}$ and $\mathrm{Pb}$ respectively.

\section{Result}

\subsection{Toxic metals in different components of cigarettes}

The analysis of 5 different IBCs for three toxic in different components of cigarette (filler tobacco, filter) pre-smoked and (filter and ash) post-smoked were determined by ICP-AES. The TE metals $(\mathrm{Cd}, \mathrm{Ni}$ and $\mathrm{Pb}$ ) obtained from filler tobacco, ash and filter of IBC origin, showed a wide variation with regard to concentration levels of three TEs. The information about cigarettes are given in Table 2. The mean values of each TE were calculated on the basis of weight of each studied cigarette brands (Table 2). The results of TEs in different component of BCs were expressed as mean \pm SD as shown in Table 6.

The filler tobacco of different $\mathrm{BCs}$ of different batches contains $\mathrm{Cd}, \mathrm{Ni}$ and $\mathrm{Pb}$ concentrations in the ranges of 1.73-2.02, 0.715-1.52 and 0378-1.16 pg/cigarette, respectively (Table 6). It was observed that the understudy analytes were not detected in filter of cigarette before smoking.

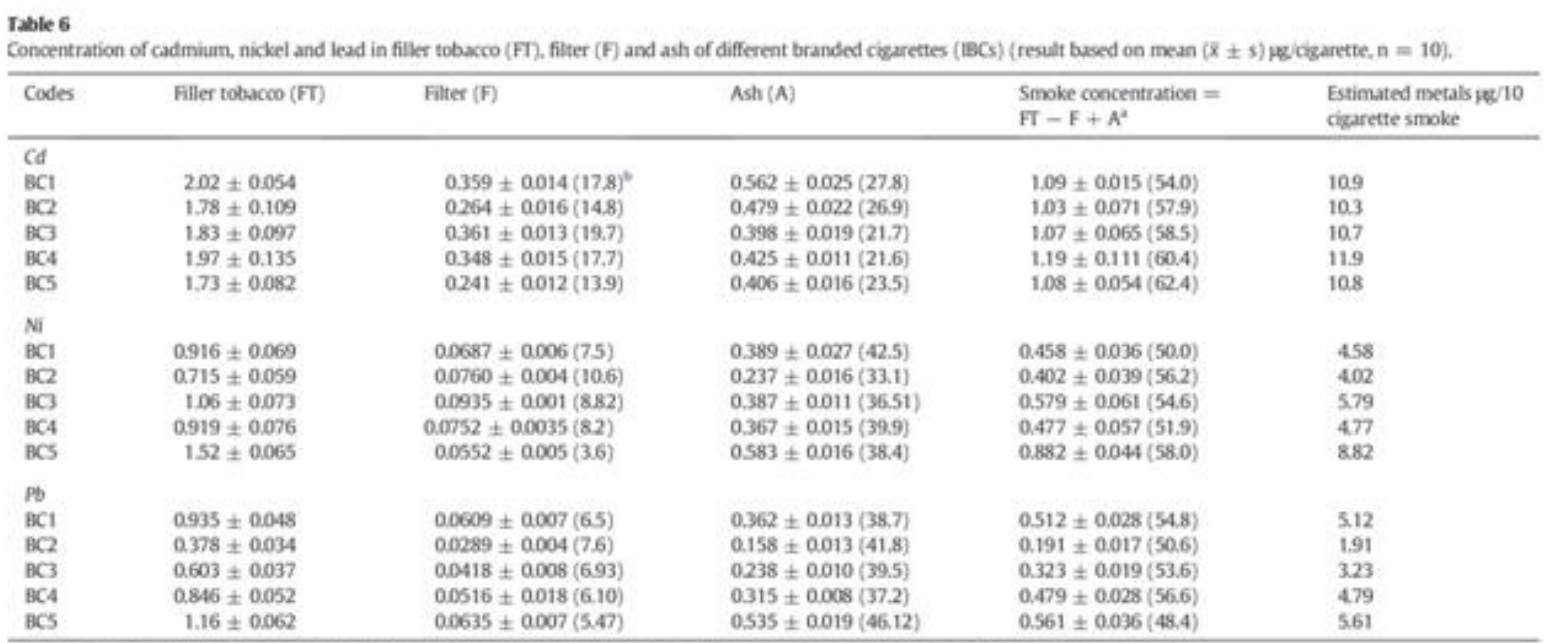

- Concentration of TMs in smoke obtained from total content in filler tobacco minus concentration of filter and ash values of same cigarette.

- Values in parenthesis is $(\boldsymbol{X})$ of toxic metals in different components of cigarette with related to tocal contents in filler tobacca 
After smoking the percentage of $\mathrm{Cd}, \mathrm{Ni}$ and $\mathrm{Pb}$ absorbed and trapped by filter of different branded cigarettes were found in the ranges of 13.9-19.7, 3.6-8.82 and 5.47-7.60 $\mu \mathrm{g} / \mathrm{cigarette}$, respectively, of total metals content observed in FT (Table 6). The percentage of $\mathrm{Cd}$, Ni and $\mathrm{Pb}$ in ash of all studied cigarettes, were observed in the ranges of 21.6-27.8, 33.1-42.5 and 37.2-46.12 $\mu \mathrm{g} /$ cigarette, of total contents of FT, respectively (Table 6). The concentration of TEs in FT were higher than those in the ash, these results are consistent with other study [21]. Cigarette ash plays an important role in terms of toxic metal distribution towards human health and environmental pollution.

The changes in the composition of tobacco, ash and filter of cigarettes of various brands are associated with peculiarity of tobacco plant varieties and tobacco processing. There is no significant difference in average concentration of $\mathrm{Cd}$ in all branded cigarettes tested, ranging from 1.73 to $2.02 \mu \mathrm{g} /$ cigarette (Table 6). The minimum amount of Cd was observed in IBC5 (John Player blue), while highest amount was also observed in IBC1 (Dunhill).

As compared with the reported results for Cd in the United Kingdom $(0.90 \mu \mathrm{g} / \mathrm{g})$ and Korean cigarettes $(1.02 \mu \mathrm{g} / \mathrm{g})$, the average Cd contents in all cigarette brands are 1.74-2.20 times higher than those of United Kingdom and Korea, respectively [22], but lower than some branded cigarettes of Jordan [23]. The levels of $\mathrm{Pb}$ in 5 branded cigarette was found in the range of $0.378-1.16 \mu \mathrm{g} /$ cigarette corresponding to $0.676-1.67 \mu \mathrm{g} / \mathrm{g}$ of filler tobacco. The average $\mathrm{Pb}$ contents in studied cigarette of different brands are comparable with literature reported values of $\mathrm{Pb}$ [22], while 3 fold lower than those results of $\mathrm{Pb}$ in tobacco of cigarette reported by Massadeh et al. (2.10 to $3.23 \mu \mathrm{g} / \mathrm{g}$ ) [23]. The resulted data of toxic elements indicated that by smoking 10 cigarettes of different brands in a day, inhaled 10.3-11.9, 4.028.82 and 1.91-5.61 $\mu \mathrm{g}$ of $\mathrm{Cd}, \mathrm{Ni}$ and $\mathrm{Pb}$, respectively, by the smoker or spreads into the environment.

\subsection{Toxic metals in biological samples of controls and HT patients}

In the study population, more than $50 \%$ of controls and hypertensive patients were smokers. Blood pressure of controls and patients were measured according to standard protocol, in the sitting position after a 5-min rest. A patient was diagnosed as hypertensive if systolic blood pressure was $150 \mathrm{~mm} \mathrm{Hg}$, and diastolic pressure was $90 \mathrm{~mm} \mathrm{Hg}$. The other physical parameters of both groups of patients and con-trols were obtained by standard methods as shown in Table 4. The weight and body mass index of HT patients were not significantly different as compared to controls of both gender ( $p>0.05$ ). The blood pressure (systolic and diastolic blood pressure) of HT patients was significantly higher than those in nonhypertensive controls of same age group $(\mathrm{p}<0.05)$.

The elemental contents in the biological (scalp hair \& blood) samples varied widely among individuals; thus, a significantly large number of samples were required for statistical interpretation of the data to achieve a meaningful correlation between physiological disorders and concentrations of TEs. 


\begin{tabular}{|c|c|c|c|c|}
\hline \multirow[t]{2}{*}{ Parameters } & \multicolumn{2}{|l|}{ Controls } & \multicolumn{2}{|l|}{ HT Patients } \\
\hline & $\mathrm{CNS}^{4}$ & $\mathrm{cs}^{b}$ & PNS & PS $^{d}$ \\
\hline \multicolumn{5}{|c|}{ Scolp hair (1/g/g) } \\
\hline \multicolumn{5}{|l|}{ Male } \\
\hline Cd & $0.65 \pm 0.14$ & $1.49 \pm 0.19$ & $2.17 \pm 0.14$ & $2.62 \pm 0.18$ \\
\hline $\mathrm{Ni}$ & $1.78 \pm 0.29$ & $3.32 \pm 0.34$ & $3.89 \pm 0.38$ & $6.20 \pm 0.44$ \\
\hline $\mathrm{Pb}$ & $3.38 \pm 0.35$ & $4.85 \pm 0.29$ & $5.31 \pm 0.25$ & $7.45 \pm 0.33$ \\
\hline \multicolumn{5}{|l|}{ Female } \\
\hline cd & $0.56 \pm 0.08$ & $1.37 \pm 0.10$ & $2.03 \pm 0.17$ & $2.48 \pm 0.15$ \\
\hline $\mathrm{Ni}$ & $1.62 \pm 0.41$ & $350 \pm 0.47$ & $3.40 \pm 0.43$ & $5.62 \pm 0.33$ \\
\hline $\mathrm{Pb}$ & $3.26 \pm 0.28$ & $4.47 \pm 0.18$ & $5.19 \pm 0.20$ & $7.30 \pm 0.27$ \\
\hline \multicolumn{5}{|l|}{ Bbood ( $\mathrm{gg} / \mathrm{I})$} \\
\hline \multicolumn{5}{|l|}{ Male } \\
\hline cd & $3.53 \pm 0.61$ & $5.23 \pm 0.28$ & $5.79 \pm 0.62$ & $8.86 \pm 0.74$ \\
\hline $\mathrm{Ni}$ & $1.81 \pm 0.39$ & $3.70 \pm 0.48$ & $3.62 \pm 0.29$ & $6.25 \pm 0.74$ \\
\hline $\mathrm{Pb}$ & $192 \pm 158$ & $271 \pm 18.4$ & $373 \pm 20.6$ & $516 \pm 17.5$ \\
\hline \multicolumn{5}{|l|}{ Female } \\
\hline $\mathrm{Cd}$ & $3.36 \pm 0.45$ & $5.16 \pm 0.42$ & $5.54 \pm 0.49$ & $8.65 \pm 0.70$ \\
\hline $\mathrm{Ni}$ & $1.64 \pm 0.18$ & $359 \pm 0.27$ & $3.53 \pm 0.24$ & $6.11 \pm 0.58$ \\
\hline $\mathrm{Pb}$ & $183 \pm 156$ & $257 \pm 15.7$ & $358 \pm 17.8$ & $502 \pm 20.6$ \\
\hline $\begin{array}{l}\text { Control no } \\
\text { Control sm } \\
\text { \&atient nor } \\
\text { \& Patient sm }\end{array}$ & $\begin{array}{l}\text { olers. } \\
\text { rs. } \\
\text { okers. } \\
\text { rs. }\end{array}$ & & & \\
\hline
\end{tabular}

The mean concentrations with standard deviations for each element in biological samples, as shown in Table 7, indicate that the concentrations of TEs $(\mathrm{Cd}, \mathrm{Ni}$ and $\mathrm{Pb}$ ) were altered in the scalp hair and blood samples of smoker hypertensive patients. An elevated level of $\mathrm{Cd}$ content was observed in the scalp hair of male and female CS. The ranges of $\mathrm{Cd}$ in the scalp hair samples of male control nonsmokers (CNS) and control smokers CS were found at 95\% confidence intervals (CI: 0.57-0.72 and CI: $1.40-1.60 \mu \mathrm{g} / \mathrm{g}$, respectively),

whereas those in male patient nonsmokers (PNS) and patient smokers (PS) have CI: 2.07$2.25 \mathrm{ug} / \mathrm{g}$ and CI: 2.53-2.73 $\mu \mathrm{g} / \mathrm{g}$, respectively ( $<0.002$ ) (Table 7). The concentrations of $\mathrm{Cd}$ in the blood samples of male CNS and CS were significantly lower (CI: 3.25, 3.80 and CI: 5.09, $5.37 \mu \mathrm{g} / \mathrm{l}$, respectively), compared with those in male PNS and PS (CI: 5.48, 6.10 and CI: $8.54,9.23 \mu \mathrm{g} / \mathrm{l}$, respectively), with $\mathrm{p}<0.003$. The same trend was observed in female cases (Table 7).

The $\mathrm{Pb}$ concentrations in the scalp hair samples of male and female CNS and CS were found to be CI: 3.20, 3.53 and CI: 4.70, 4.98, and CI: 3.13, 3.39 and CI: 4.40, $4.58 \mathrm{pg} / \mathrm{g}$, respectively whereas in the male and female PNS and PS, the Pb levels were in the range of CI: 5.16, 5.45 and CI: 7.27, 7.62, and CI: 5.10, 5.29 and CI: 7.16, $7.40 \mu \mathrm{g} / \mathrm{g}$, respec-tively (Table 7). Similarly, a higher levels of $\mathrm{Pb}$ was observed in the blood samples of male and female PNS and PS (CI: 363, 382 and CI: 507, 525, and CI: 350, 365 and CI: 492, 510 pg/l respectively) than in male and female CNS and CS (CI: 185, 200 and CI: 263, 280, and CI: 175, 189 and CI: 249, $264 \mu \mathrm{g} / 1$, respectively) $(\mathrm{p}<0.001)$ (Table 7).

The levels of Ni in the scalp hair samples of male and female PNS and PS were found to be CI: 3.70, 4.07 and CI: 6.00, 6.43, and CI: 3.22, 3.62 and CI: 5.48, 5.84 pg/g, respectively. 
While male and female CNS and CS, the Ni levels were in the range of CI: 1.64, 1.95 and CI: 3.15, 3.50, and CI: 1.41, 1.80 and CI: 3.27, $3.72 \mu \mathrm{g} / \mathrm{g}$, respectively (Table 7).

The resulted data indicated that the scalp hair of smoker controls and hypertensive patients have two fold higher level of $\mathrm{Ni}$, as compared to healthy and nonsmoker patients $(\mathrm{p}<0.001)$. The ranges of Ni concentration in the blood samples of male and female CNS and CS (CI: 1.62, 1.99 and CI: 3.46, 3.95, and CI: 1.45, 1.74 and CI: 3.45, 3.75), were found to be lower as compared to male and female PNS and PS (CI: 3.48, 3.77 and CI: 5.90, 6.53, and CI: 3.41, 3.65 and CI: 5.83, $6.40 \mu \mathrm{g} / \mathrm{l}$, respectively) ( $\mathrm{p}>0.002$ ) (Table 7). The unpaired student t test at different degrees of freedom between hypertensive patients and controls of both genders were calculated at different probabilities. Our calculated $t$ value exceeds that of $t$,,ducal value at 95\% confidence intervals, which indicated the significant differences between mean values of understudy TEs in controls and hypertensive patients $(\mathrm{p}<0.001)$.

\section{Discussion}

This study provides data on TEs $(\mathrm{Cd}, \mathrm{Ni}$ and $\mathrm{Pb})$ in scalp hair and blood samples obtained from smoker hypertensive and non-hypertensive controls of both genders of age group (30-50 years). There are many causes of high blood pressure, but cigarette smoking is also an important risk factor, considering that $60 \%$ of all the studied patients were smokers (Table 4 ). Tobacco-related disease originates from the biological consequences of repeated inhalation exposure to numerous toxic constituents including TEs in cigarette smoke, which are produced by pyrosynthesis or liberated during combustion. According to world health organization (WHO) every $10 \mathrm{~s}$, another person dies as a result of tobacco use in the world [24]. TEs uptake by tobacco plants depends on the concentration of these toxicants in the soil, soil amendments with sewage sludge and soil $\mathrm{pH}[25]$.

It is likely that cigarettes made from tobacco grown in various geographical regions or under different agricultural conditions will have different levels of the heavy metals in the tobacco filler and thus, generate different levels in the smoke [26,27]. Tobacco leaves naturally accumulate and concentrate relatively high levels of toxic heavy metals and therefore smoking of tobacco is an important source of these metals exposure for smokers [26]. The investigated data indicates that smokers could receive signifi-cantly higher exposures to TEs $(\mathrm{Cd} \mathrm{Pb}$ and $\mathrm{Ni})$ from different $\mathrm{BCs}$. The country of origin and type of the product play major roles in determining the chemical composition of cigarette tobacco [28]. Tobacco plants have a profound ability to absorb $\mathrm{Cd}$ from the soil and accumulate it in high concentrations in the leaves and can lead to human exposure to this carcinogenic metal [29].

The $\mathrm{Cd}$ is the best studied metal from cigarette smoke, and smoking is the main source of $\mathrm{Cd}$ intake by humans. Although the $\mathrm{Cd}$ amounts varied, the average $\mathrm{Cd}$ content per cigarette lies between 0.5 and $1.5 \mathrm{mg} /$ cigarette [30]. The $\mathrm{Pb}$ may also be present in high concentrations in tobacco smoke. Smokers have considerably higher blood Pb levels than nonsmokers [31]. The Ni reacts with carbon monoxide in tobacco smoke to form a highly toxic carbonyl compound, which is believed to be a potential carcinogen. The amount of $\mathrm{Ni}$ in the tobacco 
plant lies between 0.640 and $1.15 \mathrm{lug} / \mathrm{g}$, and varies greatly in cigarettes of different brands [32]. The levels of $\mathrm{Cd}, \mathrm{Pb}$ and $\mathrm{Ni}$ passed to the smokes of 10 cigarettes of different brands were estimated to be 103-11.9, 4.02-8.82 and 1.91-5.61 [tg/10 cigarettes respectively (Table 4 ), either passed into mainstream or side stream smoke. It was investigated that one pack of cigarettes deposits 2-4 lug $\mathrm{Cd}, 1-2$ lig $\mathrm{Pb}$ and $\mathrm{Ni}$ into the lungs of a smoker, whereas some of the smoke passes into the air to be inhaled by smokers and nonsmokers alike [28].

Our resulted data indicated that smoker HT patients and controls have increase levels of all three TEs in blood and scalp hair samples, which were may be associated with increasing prevalence of hypertension in both genders. Some epidemiologic studies have found positive associations between body Cd levels and elevated blood pressure or hypertension [33-36]. It was reported in literature that both active and passive smoking [37] are associated with the development of several clinical disorders, that alters LDL (low-density lipoprotein) [38], reducing the endothelium-dependent relaxation induced by acetylcholine. TEs may deplete glutathione and protein-bound sulfhydryl groups, resulting in the production of reactive oxygen species, such as superoxide anion, hydrogen peroxide and hydroxyl radical [39].

It was reported in previous study that TEs have antagonistic effect with essential trace elements like zinc ( $\mathrm{Zn})$ and calcium $(\mathrm{Ca})$. It was investigated that the accumulation of $\mathrm{Cd}$ in the human body may replace $\mathrm{Zn}$ in the arteries, which contributes to arteries becoming brittle and inflexible. Once the arteries become inflamed and brittle, the body may coat them with $\mathrm{Ca}$ and fatty plaques to prevent their rupture [40]. This plaque unfortunately reduces the interior diameter of the arteries, resulting in more pressure being required to force the blood through the smaller diameter arteries, which in turn raises blood pressure [41]. The Pb may also be present in high concentrations in tobacco smoke. Smokers have considerably higher blood $\mathrm{Pb}$ levels than nonsmokers. It was observed that smoker patients and controls have considerably higher levels of $\mathrm{Pb}$ in their blood and scalp hair than do nonsmokers, these results are consisted with previous study [42].

The children are more sensitive to the toxic effects of $\mathrm{Pb}$ compared with adults and passive smoking plays an important role in exposure of children to $\mathrm{Pb}$ [43]. Other possible health consequences of $\mathrm{Pb}$ accumulation are $\mathrm{HT}$ and peripheral arterial diseases. The $\mathrm{Pb}$ may also replace $\mathrm{Zn}$ and $\mathrm{Ca}$, contributing to the severity of HT problems [41]. In vitro and in vivo studies suggested that $\mathrm{Pb}$-induced oxidation contributes to red blood cell damage [44]. The $\mathrm{Pb}$ and $\mathrm{Cd}$ may also replace $\mathrm{Zn}$ and $\mathrm{Ca}$ contributing to the sever-ity of HT problems due to accumulate in kidneys, which damage their ability to regulate the water balance in the body. This can lead to water retention, salt retention and high blood pressure [42]. These both TEs may also stimulate the production of inflammatory cytokines and may induce endothelial damage by down regulating the production of nitric oxide [45].

It was observed in our study that the level of Ni was significantly ( $\mathrm{p}<0.001)$ higher in smoker hypertensive patients and controls than in nonsmoker study population (Table 7). Besides this, the inhalation of vapors of $\mathrm{Ni}$ carbonyl obtained from burning of tobacco and from certain occupations (welding, fitting and so on) may also cause elevated Ni levels in biological samples [46]. As is the case with $\mathrm{Cd}$, tobacco plants absorb Ni from the soil and 
concentrate it in the leaves [43]. The Ni has been examined either alone or in combination with $\mathrm{Cd}$ [47]. The $\mathrm{Ni}$ as a trace element that is 'probably' essential, given its role in $\mathrm{Ni}$ containing enzymes found in plants and microorganisms.

However, evidence that $\mathrm{Ni}$ has similar functions in humans is not currently available. In contrast, Ni compounds can display tumor promoting capability via a number of mechanisms including inhibition of intercellular communication, the induction of DNA deletions and aberrations, production of DNA-protein cross-links, oxidative damage, inhibition of nucleotide excision repair and an increase in DNA methylation leading to inactivation of gene expression [48]. Ni has long been known to produce nasal, prostate and lung cancers in relation to its high occupational exposure [32]. In studied area, a survey study by us confirmed that the rate of hypertension incidence is prevalent in smokers.

\section{Conclusions}

This study provided a new data for the health authorities in Ireland. The results of toxic elements $(\mathrm{Cd}, \mathrm{Ni}, \mathrm{Pb})$ in different branded cigarettes consumed in Ireland, confirmed that tobacco is a notable source of their exposure to the general population. In the present study we only dem-onstrate that there was a significant association between toxic elements in blood and scalp hair of smoker and nonsmoker hypertensive patients and controls but the prevalence being more in smoker patients. The higher levels of $\mathrm{Cd}, \mathrm{Pb}$ and $\mathrm{Ni}$, correlated well with the consequences of hypertension. This study provides some support for the hypothesis that dietary intake of toxic elements most probably through smoking cigarette, may increase the risk of hypertension and related physiological disorders, which indicates that the causal link may be stronger among cigarette smokers. It was recommended that the TEs measurements may be performed on patients reaching in the emergency department, to test whether their concentration may serve not only as markers of hypertension and its remedies but also as predictors of adverse outcomes. Further studies may be useful to infer a causal relationship between TEs exposure from tobacco smoke in addition to other sources (food, water and atmosphere) and hypertension.

\section{Acknowledgment}

Dr. Hassan Imran Afridi thank the Higher Education Commission (HEC) of Pakistan for providing the scholarships for the post doctoral research work. Dr. H.I. Afridi is also thankful to the National Center of Excellence in Analytical Chemistry, University of Sindh, Jamshoro, Pakistan for the grant of sabbatical leave. 


\section{References}

[1] Burt VL Whelton P, Roccella EJ, Brown C, Cutler JA, Higgins M, et al. Prevalence of hypertension in the US adult population. Results from the Third National Health and Nutrition Examination Survey, 1988-1991. Hypertension 1995;25:305-13.

[2] Privitera JR, Stang A. Silent clots-life's biggest killers. Covina, CA, USA: The Catacombs Press; 1996. p. 1-55.

[3] American Academy of Pediatrics October 1998 Child Health Month Report. The risks of tobacco use: a message to parents and teens; Milam JE. Perceived invulnerability and cigarette smoking among adolescents. Addict Behav 2000;25:71-80.

[4] Kazi TG, Jalbani N, Kazi N, Jamali MK, Arain MB, Afridi HI, et al. Evaluation of toxic metals in blood and urine samples of chronic renal failure patients, before and after dialysis. Ren Fail 2008:30:737-45.

[5] Kazi TG, Memon AR, Afridi HI, Jamali MK, Arain MB, Jalbani N, et al. Determination of cadmium in whole blood and scalp hair samples of Pakistani male lung cancer pa-tients by electro thermal atomic absorption spectrometer. Sd Total Environ 2008;389:270-6.

[6] Fitzpatrick TM, Blair EA. Smoking and pulmonary and cardiovascular disease: upper airway complications of smoking. Clin Chest Med 2000;21:147-57.

[7] Kozlowski LT, Connor RJ. Cigarette filter ventilation is a defective design because of misleading taste, bigger puffs, and blocked vents. Tob Control 2002;11:140-50.

[8] Wagner GJ. Accumulation of cadmium in crop plants and its consequences to human health. Adv Agron 1993;51:173-212.

[9] Afridi HI, Kazi TG, Brabazon D, Naher S. Interaction between zinc, cadmium, and lead in scalp hair samples of Pakistani and Irish smokers rheumatoid arthritis subjects in relation to controls. Biol Trace Elem Res 2012;148:139-47.

[10] Reilly C. Metal contamination of food: its significance for food quality and human health. Oxford, UK: Blackwell Science Ltd; 2002.

[11] Csalari J, Szantai K. Transfer rate of cadmium, lead, zinc and iron from the tobacco-cut of the most popular Hungarian cigarette brands to the combustion products. Acta Aliment 2002;31:279-88.

[12] Witte KK, Clark AL, Cleland JG. Chronic heart failure and micronutrients. J Am Coll Cardiol 2001;37:1765-74.

[13] Nawrot TS, Thijs L, Den Hond EM, Roels HA, Staessen JA. An epidemiological reappraisal of the association between blood pressure and blood lead: a metaanalysis. J Hum Hypertens 2002;16:123-31. 
[14] Witte KK, Nikitin NP, Parker At von Haehling S, Volk HD, Anker SD, et al. The effect of micronutrient supplementation on quality-of-life and left ventricular function in elderly patients with chronic heart failure. Eur Heart J 2005;26:2238-44.

[15] Tuzen M. Determination of some trace elements in whole blood and serum by GFAAS. Trace Elem Electrolyte 2002;19(4):202-4.

[16] Kazi TG, Afridi HI, Kazi N, Jamali MK, Arain MB, Sarfraz RA, et al. Distribution of zinc, copper and iron in biological samples of Pakistani myocardial infarction (1st, 2nd and 3rd heart attack) patients and controls. Clin Chim Acta 2008;389:114-9.

[17] Tuzen M, Soylak M. Multi-element coprecipitation for separation and enrichment of heavy metal ions for their flame atomic absorption spectrometric determinations. J Hazard Mater 2009;162:724-9.

[18] Citak D, Tuzen M. A novel preconcentration procedure using cloud point extraction for determination of lead, cobalt and copper in water and food samples using flame atomic absorption spectrometry. Food Chem Toxicol 2010,48(5):1399-404.

[19] Kazi TG, Afridi HI, Jamali MK, Kazi GH, Arain MB, Jalbani N, et al. Analysis of heavy metals in scalp hair samples of hypertensive patients by conventional andmicrowave digestion methods. Spectrosc Lett 2006;39:203-14.

[20] Afridi HI, Kazi TG, Kazi N, Jamali MK, Arain MB, Jalbani N, et al. Evaluation of status of toxic metals in biological samples of diabetes mellitus patients. Diabetes Res Clin Pract 2008;80:280-8.

[21] Ebisike K, Ayejuyo 00, Sonibare JA, Ojumu TV. Pollution impacts of cigarette consumption on indoor air quality in Nigeria. J Appl Sci 2004;4:623-9.

[22] Jung MC, Thornton I, Chon T. Arsenic, cadmium, copper and lead concentrations in cigarettes produced in Korea and the United Kingdom. Environ Technol 1998;19:237-41.

[23] Adnan M, Massadeh FQ Alali Q Jaradat M. Determination of cadmium and lead in different cigarette brands in Jordan. J Environ Monit 2005;104:163-70.

[24] Reilly C. Metal contamination of food: its significance for food quality and human health. Oxford, UK: Blackwell Science Ltd; 2002.

[25] Mulchi CL, Adamu CA, Bell PF, Chaney RL Residual heavy metal levels in sludge amended coastal plain soils. IL Predicting metal levels in tobacco from soil test infor-mation. Commun Soil Sci Plant Anal 1992;23:1053-69.

[26] Csalari J, Szantai K. Transfer rate of cadmium, lead, zinc and iron from the tobacco-cut of the most popular Hungarian cigarette brands to the combustion products. Acta Aliment 2002;31:279-88. 
[27] Hecht SS. Tobacco carcinogens, their biomarkers and tobacco-induced cancer. Nat Rev Cancer 2003;3:733-44.

[28] Kazi TG, Jalbani N, Arain MB, Jamali MK, Afridi HI, Sarfraz RA, et al. Toxic metals dis-tribution in different components of Pakistani and imported cigarettes by electro-thermal atomic absorption spectrometer. J Hazard Mater 2009;163:302-7.

[29] Lugon MN, Martin F, Krauss MR, Ramey PB, Rossi L. Cadmium concentration in tobacco (Nicotiana tabacum L.) from different countries and its relationship with other elements. Chemosphere 2006;63:1074-86.

[30] Satarug S, Moore MR. Adverse health effects of chronic exposure to lowlevel cadmium in foodstuffs and cigarette smoke. Environ Health Perspect 2004;112:1099-103.

[31] Chiba M, Masironi R. Toxic and trace elements in tobacco and tobacco smoke. Bull World Health Organ 1992;70:269-75.

[32] William TH, Andersen ZI. Cigarette smoking and nickel exposure. J Environ Monit 2003;5: 198-201.

[33] Satarug S, Nishijo M, Ujjin P, Vanavanitkun Y, Moore MR Cadmium-induced nephropathy in the development of high blood pressure. Toxicol Lett 2005;157:57-68.

[34] Al-Saleh I, Shinwari N, Mashhour A, Mohamed GD, Ghosh MA, Shammasi Z, et al. Cadmium and mercury levels in Saudi women and its possible relationship with hypertension. Biol Trace Elem Res 2006;112:13-29.

[35] Eum KD, Lee MS, Paek D. Cadmium in blood and hypertension. Sci Total Environ 2008;407:147-53.

[36] Tellez-Plaza M, Navas-Acien A, Crainiceanu CM, Guallar E. Cadmium exposure and hypertension in the 1999-2004 National Health and Nutrition Examination Survey (NHANES). Environ Health Perspect 2008;116:51-6.

[37] Kawachi I, Colditz GA, Speizer FE, Manson JE, Stampfer MJ, Willett WC, et al. A prospec-tive study of passive smoking and coronary heart disease. Circulation 1997;95:23749.

[38] Kagota S, Yamaguchi Y, Shinozuka K, Kwon YM, Kunitomo M. Cigarette smoke-modified low density lipoprotein impairs endothelium-dependent relaxation in isolated rabbit arteries. Gen Pharmacol 1996;27:477-81.

[39] Goyer RA. Toxic effects of metals. In: Klaassen CD, editor. Casarett and Doull's toxicology: the basic science of poisons. New York: McGraw-Hill; 1996. p. 691-736.

[40] Cohen N, Golik A. Zinc balance and medications commonly used in the management of heart failure. Heart Fail Rev 2006;11:19-24. 
[41] Navas-Acien A, Selvin E, Sharrett AR, Calderon-Aranda E, Silbergeld E, Guallar E. Lead, cadmium, smoking, and increased risk of peripheral arterial disease. Circula-tion 2004;109:3196-201.

[42] Staessen JA, Roels H, Fagard R. Lead exposure and conventional and ambulatory blood pressure: a prospective population study, Phee Cad Investigators. JAMA 1996;275:1604-6.

[43] Mannino DM, Albalak R, Grosse S, Repace J. Secondhand smoke exposure and blood lead levels in US children. Epidemiology 2003;14:719-27.

[44] Ding Y, Gonick HC, Vaziri ND. Lead promotes hydroxyl radical generation and lipid peroxidation in cultured aortic endothelial cells. Am J Hypertens 2000;13:552-5.

[45] Demontis MP, Varoni MV, Volpe AR, Emanueli C, Madeddu P. Role of nitric oxide synthase inhibition in the acute hypertensive response to intra cerebroventricular cadmium. Br J Pharmacol 1998;123:129-35.

[46] Tian 4 Lawrence DA. Metal-induced modulation of nitric oxide production in vitro by murine macrophages: lead, nickel and cobalt utilize different mechanisms. Toxicol Appl Pharmacol 1996;141:540-7.

[47] Jarup L, Bellander T, Hogstedt C, Spang G. Mortality and cancer incidence in Swedish battery workers exposed to cadmium and nickel. Occup Environ Med 1998;55:755-9.

[48] Lee YW, Klein CB, Kargacin B. Carcinogenic nickel silences gene expression by chromatin condensation and DNA methylation: a new model for epigenetic carcinogens. Mol Cell Biol 1995;15:2547-57. 